\title{
RANCANG BANGUN MODEL KETEL PIPA API KAPASITAS 20 KG/JAM TEKANAN 3 BAR(GAUGE) KONDISI SATURASI
}

\author{
Paul Aldrich Martua Nainggolan, Ir. M. Syahril Gultom. MT. \\ Departemen Teknik Mesin, Fakultas Teknik, Universitas Sumatera Utara \\ paulnainggolan@yahoo.com
}

\begin{abstract}
Steam is generated in a steam generator or Boiler. The task of this thesis is to design a model of a fire tube boiler boiler capacity of $20 \mathrm{~kg}$ per hour and work pressure of 3 barg and for this design use LPG fuel. From the calculations obtained the amount of fuel consumption of 1.58 $\mathrm{kg} / \mathrm{hour}$ with a total combustion heat of $74665.75 \mathrm{~kJ} / \mathrm{hour}$ and through the analysis of the components of the combustion product, the flame temperature of $1957.44^{\circ} \mathrm{C}$ was obtained. The percentage of heat transformed is $32232,19 \mathrm{~kJ} /$ hour or $8953,38 \mathrm{~W}$ or $43.16 \%$ of the total heat of combustion with the heat transfer area on the funnel I passage is $0.06 \mathrm{~m}^{2}$, for route II the percentage of heat is $13477.4 \mathrm{~kJ} /$ hour or $3743.72 \mathrm{~W}$ or $18.05 \%$ of the total heat of combustion with an area of heat transfer is $0.136 \mathrm{~m}^{2}$ with a total heat transfer coefficient of $53.57 \mathrm{~W} / \mathrm{m}^{2} . K$, and passage III percentage of heat $4780.13 \mathrm{~kJ} / \mathrm{hour}$ or $1332.45 \mathrm{~W}$ or $6.4 \%$ of the total heat of combustion with the area of the heat transfer area is $0.120 \mathrm{~m}^{2}$ with a total heat transfer coefficient of $46.28 \mathrm{~W} / \mathrm{m}^{2} . K$, and the diameter of the drum/sleeve is $0.315 \mathrm{~m}$ and the length of each is 0,5 m. Then the efficiency of Steam Boilers is 67.61\%. In making fire tube boiler, the material used is carbon steel. From the test results obtained data that is, average fuel consumption $1.45 \mathrm{~kg} /$ hour, average steam capacity of $15.4 \mathrm{~kg} / \mathrm{hour}$, and 59\% efficiency.
\end{abstract}

Keywords: Boiler, fire tube boiler, heat transfer, efficiency

\begin{abstract}
ABSTRAK
Uap dihasilkan dalam pembangkit uap atau Boiler. Tugas skripsi ini untuk rancang bangun sebuah model ketel pipa api kapasitas $20 \mathrm{~kg}$ per jam dan tekanan kerja 3 barg dan untuk perancangan ini digunakan bahan bakar LPG. Dari perhitungan-perhitungan diperoleh jumlah konsumsi bahan bakar sebesar 1,58 kg/jam dengan total panas pembakaran sebesar 74665,75 $\mathrm{kJ} / \mathrm{jam}$ dan melalui analisis komponen-komponen produk pembakaran maka diperoleh temperatur nyala api $1957,44^{\circ} \mathrm{C}$. Persentase panas yang ditransformasikan adalah 32232,19 $\mathrm{kJ} / \mathrm{jam}$ atau $8953,38 \mathrm{~W}$ atau 43,16\% dari total panas pembakaran dengan luas bidang perpindahan panas pada laluan I corong api adalah $0,06 \mathrm{~m}^{2}$, untuk laluan II persentase panas $13477,4 \mathrm{~kJ} / \mathrm{jam}$ atau $3743,72 \mathrm{~W}$ atau $18,05 \%$ dari total panas pembakaran dengan luas bidang perpindahan panas adalah $0,136 \mathrm{~m}^{2}$ dengan total koefisien perpindahan panas sebesar 53,57 $\mathrm{W} / \mathrm{m}^{2} . \mathrm{K}$, dan laluan III persentase panas $4780,13 \mathrm{~kJ} / \mathrm{jam}$ atau $1332,45 \mathrm{~W}$ atau $6,4 \%$ dari total panas pembakaran dengan luas bidang perpindahan panas adalah $0,12 \mathrm{~m}^{2}$ dengan total koefisien perpindahan panas sebesar $46,28 \mathrm{~W} / \mathrm{m}^{2} . \mathrm{K}$, serta diameter drum/selongsong adalah $0,315 \mathrm{~m}$ dan panjang masing-masing 0,5 m. Maka efisiensi Ketel Uap sebesar 67,61\%. Dalam pembuatan ketel pipa api, bahan yang digunakan adalah baja karbon. Dari hasil pengujian diperoleh data yaitu, konsumsi bahan bakar rata-rata 1,45 kg/jam, Kapasitas uap rata-rata 15,4 kg/jam, dan efisiensi 59\%.
\end{abstract}

Kata kunci: Boiler, ketel pipa api, perpindahan panas, efisiensi

\section{PENDAhUluAN}


Sampai saat ini energi listrik terutama dihasilkan dengan pembangkit Listrik Tenaga Uap (PLTU) dan tentu saja butuh suatu boiler atau ketel uap yang menghasilkan uap air (steam). Selanjutnya uap air ini digunakan untuk menggerakkan turbin uap dan kemudian turbin uap digunakan memutar generator listrik yang menghasilkan energi listrik. Ketel uap ini disamping sebagai pembangkit listrik juga dapat digunakan menyediakan kebutuhan uap untuk berbagai proses seperti Pengolahan Kelapa Sawit atau PKS. Pada umumnya uap yang digunakan untuk proses Pengolahan Kelapa Sawit adalah merupakan uap bekas turbin yang disebut dengan Back Pressure Steam. Kondisi uap ini maksudnya di atas tekanan atmosfir absolut misalnya kebutuhan uap dengan tekanan sekitar $3-4$ bar.

Ketel uap (Steam Boiler) merupakan suatu tangki yang tertutup dan bertekanan yang digunakan untuk menghasilkan uap melalui perpindahan panas (konduksi/rambatan, konveksi/aliran, dan radiasi/pancaran) dengan demikian dapatlah disebutkan bahwa ketel uap ini mengubah air menjadi uap dengan proses evaporasi karena pemanasan, sehingga temperatur dan tekanan uap yang terjadi di dalam boiler atau ketel uap lebih besar dari tekanan dan temperatur udara luar, sehingga dapat menghasilkan kerja atau tenaga(power).

Kondisi-kondisi uap yang dapat dihasilkan suatu boiler atau ketel uap ialah berupa: cair mendidih/saturasi (liquid saturated), uap sangat basah, sedikit basah atau uap hampir kering (wet saturated steam), uap saturasi/kering (dry saturated steam), uap superheat, dan uap superkritis. Uap superkritis adalah kondisi di atas titik kritis dan kondisi titik kritis pada suatu keadaan di antara berbagai fase pada tekanan 221,2 Bar dan temperatur $374,15^{\circ} \mathrm{C}$.

Ketel uap atau boiler ini umumnya diklasifikasikan ke dalam dua group kelompok utama, yaitu ketel-ketel pipa api (fire-tube boilers) dan ketel-ketel pipa air (water-tube boilers).

Total panas yang ditransfer ke boiler adalah :

$$
\mathrm{Q}_{\mathrm{bb}}=\dot{\mathrm{m}}_{\mathrm{bb}} \cdot \mathrm{HV} .
$$

Dimana :

$\mathrm{Q}_{\mathrm{bb}} \quad=$ Total panas $(\mathrm{kJ} / \mathrm{kg})$

$\dot{\mathrm{m}}_{\mathrm{bb}} \quad=$ aliran massa bahan bakar $(\mathrm{kg} / \mathrm{s})$

$\mathrm{HV} \quad=$ Kandungan energi bahan bakar $(\mathrm{kJ} / \mathrm{kg})$

Pada pamanasan air dari titik 1 menjadi titik 2 (cair saturasi) maka energi panas yang dibutuhkan adalah :

$$
\mathrm{Q}_{1}=\dot{\mathrm{m}}_{\mathrm{a}} \cdot\left(\mathrm{h}_{2}-\mathrm{h}_{1}\right)
$$


dimana :

$\mathrm{Q}_{1} \quad=$ Jumlah panas yang dibutuhkan hingga air cair saturasi $(\mathrm{kJ})$

$\dot{\mathrm{m}}_{\mathrm{a}} \quad=$ massa air yang dipanaskan $(\mathrm{kg} / \mathrm{s})$

$\mathrm{h}_{1} \quad=$ Entalpi spesifik air umpan (kJkg)

$\mathrm{h}_{2} \quad=$ Entalpi spesifik cair saturasi $(\mathrm{kJ} / \mathrm{kg})$

Pada ketel uap ini perpindahan panas atau hantaran kalor (heat transfer) berlangsung dalam 3 (tiga) cara, yaitu :

- Perpindahan panas secara rambatan (conduction)

- Perpindahan panas secara aliran (convection)

- Perpindahan panas secara pancaran (radiation)

Perpindahan panas atau transformasi energi panas pada dapur boiler (furnace) dimulai dari nyala api (flame), sebagai berikut :

- Cara pancaran (Radiation) :

$$
\dot{Q}_{\mathrm{r}}=\varepsilon_{\mathrm{w}} \cdot \varepsilon_{\mathrm{f}} \cdot \mathrm{B}_{\mathrm{o}} \cdot \mathrm{A}\left[\left(\frac{\mathrm{T}_{\mathrm{f}}}{100}\right)^{4}-\left(\frac{\mathrm{T}_{\mathrm{w}}}{100}\right)^{4}\right](\mathrm{kW})
$$

dimana :

Q $\quad$ = kalor yang dipancarkan nyala api $(\mathrm{kW})$

$\varepsilon_{\mathrm{w}} \quad=$ emisivitas dinding ketel (water wall)

$\varepsilon_{\mathrm{f}} \quad=$ emisivitas nyala api

$\mathrm{T}_{\mathrm{w}} \quad=$ temperatur absolut yang terkena radiasi $(\mathrm{K})$

$\mathrm{T}_{\mathrm{f}} \quad=$ temperatur absolut nyala api (K)

$\mathrm{B}_{\mathrm{o}} \quad=$ konstanta Boltzman

A = luas permukaan yang terkena radiasi.

- Panas yang diterima oleh alat penukar kalor (Heat Exchanger), yaitu :

$$
\hat{\mathrm{Q}}_{\mathrm{e}}=\mathrm{U} \text {. A . LMTD }(\mathrm{Kw})
$$

dimana :

$\mathrm{Q}_{\mathrm{e}} \quad=$ kalor yang diterima heat exchanger $(\mathrm{kW})$

$\mathrm{U} \quad=$ koefisien perpindahan panas total $\left(\mathrm{kW} / \mathrm{m}^{2} . \mathrm{K}\right)$

A = luas bidang perpindahan panas $\left(\mathrm{m}^{2}\right)$

LMTD = logaritmik mean temperatur difference $(\mathrm{K})$

Bila dianggap gas asap mengalir pada sisi luar dari suatu pipa maka koefisien perpindahan panas total (U) dapat dihitung dengan rumus :

$$
\mathrm{U}_{\mathrm{o}}=\frac{1}{\frac{\mathrm{A}_{0}}{\mathrm{~A}_{\mathrm{i}}} \frac{1}{\mathrm{~h}_{\mathrm{i}}}+\frac{\mathrm{A}_{\mathrm{o}} \cdot \operatorname{Ln}\left(\mathrm{r}_{\mathrm{o}} / \mathrm{r}_{\mathrm{i}}\right)}{2 \pi \mathrm{kL}}+\frac{1}{\mathrm{~h}_{\mathrm{o}}}}
$$


Bila dianggap gas asap mengalir pada sisi dalam pipa maka $U$ dapat dihitung sebagai berikut :

$$
\mathrm{U}_{\mathrm{i}}=\frac{1}{\frac{1}{\mathrm{~h}_{\mathrm{i}}}+\frac{\mathrm{A}_{\mathrm{i}} \cdot \operatorname{Ln}\left(\mathrm{r}_{\mathrm{o}} / \mathrm{r}_{\mathrm{i}}\right)}{2 \pi \mathrm{kL}}+\frac{\mathrm{A}_{\mathrm{i}}}{\mathrm{A}_{\mathrm{o}}} \frac{1}{\mathrm{~h}_{\mathrm{o}}}}
$$

dimana :

$\mathrm{U}_{\mathrm{o}} \quad=$ koefisien perpindahan panas total $\left(\mathrm{W} / \mathrm{m}^{2} . \mathrm{K}\right)$

$\mathrm{U}_{\mathrm{i}} \quad=$ koefisien perpindahan panas total $\left(\mathrm{W} / \mathrm{m}^{2} . \mathrm{K}\right)$

$\mathrm{A}_{0} \quad=$ luas bidang pemanas dari luar permukaan pipa $\left(\mathrm{m}^{2}\right)$

$\mathrm{Ai}=$ luas bidang pemanas dari permukaan dalam pipa $\left(\mathrm{m}^{2}\right)$

$\mathrm{h}_{\mathrm{o}} \quad=$ koefisien perpindahan panas luas pipa $\left(\mathrm{W} / \mathrm{m}^{2} . \mathrm{K}\right)$

$\mathrm{h}_{\mathrm{i}} \quad=$ koefisien perpindahan panas dalam pipa $\left(\mathrm{W} / \mathrm{m}^{2} . \mathrm{K}\right)$

$\mathrm{r}_{\mathrm{o}} \quad=$ jari-jari luar pipa $(\mathrm{m})$

$\mathrm{r}_{\mathrm{i}} \quad=$ jari-jari dalam pipa $(\mathrm{m})$

$\mathrm{k}=$ konduktivitas thermal (W/m.K)

Selisih temperatur logaritmik rata-rata (logaritmic mean temperature diffrence) atau LMTD dapat dihitung dengan rumus :

$$
\mathrm{LMTD}=\frac{\Delta \mathrm{T}_{\max }-\Delta \mathrm{T}_{\min }}{\mathrm{l}_{\mathrm{n}}\left(\Delta \mathrm{T}_{\max } / \Delta \mathrm{T}_{\min }\right)}
$$

dimana :

$\Delta \mathrm{T}_{\max }=$ selisih suhu masuk atau keluar sistim yang maksimum $\left({ }^{\circ} \mathrm{C}\right.$ atau $\left.\mathrm{K}\right)$

$\Delta \mathrm{T}_{\min }=$ selisih suhu masuk dan keluar sistim yang minimum $\left({ }^{\circ} \mathrm{C}\right.$ atau $\left.\mathrm{K}\right)$.

\section{METODE PENELITIAN}

\subsection{Diagram Alir Penelitian}




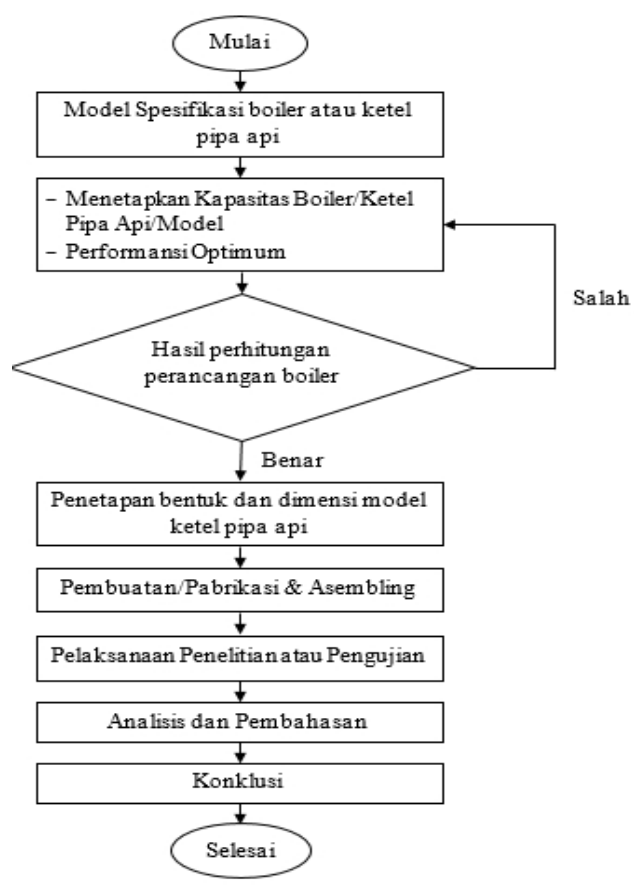

Gambar 2.1 Diagram Alir Perancangan dan Pembuatan Boiler

\subsection{Tempat dan Waktu}

Penelitian ini dilaksanakan pada bulan November - Desember 2019. Penelitian dilakukan di dua tempat, yaitu Pabrikasi dan pemasangan atau assembling boiler/ketel pipa api dilaksanakan pada bengkel Bona Pasogit di Jalan Mahkamah dan setelah selesai pemasangan dengan semua alatalat pendukungnya, boiler dibawa ke Laboratorium Mesin Fluida Universitas Sumatera Utara untuk pengujian dan pelaksanaan penelitian.

\subsection{Tahapan Penelitian}

Tahapan-tahapan pengoperasian untuk penelitian pada model boiler dilakukan sebagai berikut.

- Pengujian Dingin

- Pemanasan boiler dan Pengujian

- Pengumpulan Data

- Pengolahan Data

\section{PENGOLAHAN DATA DAN ANALISIS DATA}

\subsection{Penetapan Spesifikasi}

Spesifikasi model ketel pipa api yang dirancang sesuai dengan penetapan tugas yang diberikan adalah sebagai berikut:

- Kapasitas uap : 20 kg/jam 
- $\quad$ Tekanan uap : 3 Barg $_{\text {g }}$ (Jenuh Saturasi)

- Bahan bakar : LPG

- Nilai Kalor LPG, HHV : 47081 kJ/kg

- Kondisi suplai air : $30{ }^{\circ} \mathrm{C}$ (Normal)

- Efisiensi ketel uap : 70\% (Ditetapkan)

- $\dot{\mathrm{m}}_{\mathrm{bb}}: 1,5859 \mathrm{~kg} / \mathrm{jam}$

\subsection{Ketel Pipa Api 3 Laluan}

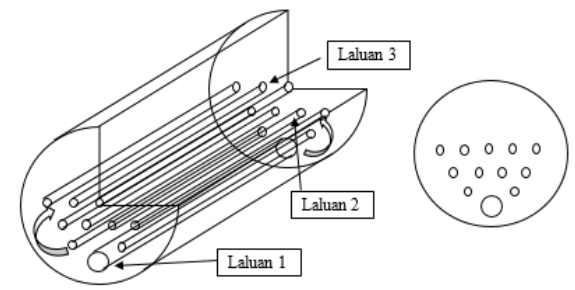

Gambar 3.1 Ketel Pipa Api 3 Laluan

- Lorong Api atau Laluan I

- $\mathrm{L} \quad=0,5 \mathrm{~m}=50 \mathrm{~cm}$

- $\mathrm{D}=5 \mathrm{~cm}$

- Pipa-pipa Gas Asap (laluan II)

- $\mathrm{D}=1,905 \mathrm{~cm}$

- $\mathrm{L} \quad=50 \mathrm{~cm}$

- $\mathrm{n} \quad=6$ buah

- Pipa-pipa Gas Asap (laluan III) :

- $\mathrm{D}=1,905 \mathrm{~cm}$

- $\mathrm{L} \quad=50 \mathrm{~cm}$

- $\mathrm{n} \quad=5$ buah

- Drum

- Panjang Drum $=60 \mathrm{~cm}$

- Diameter $=31,5 \mathrm{~cm}$

- Tebal drum $=0,64 \mathrm{~cm}$

- Cerobong asap

- Tinggi $=1 \mathrm{~m}$

- Diameter = 2 inchi

- Isolasi

- Tebal isolasi $=5 \mathrm{~cm}$ 


\subsection{Data Pengujian dan Pembahasan}

Untuk pengambilan data operasi atau parameter-parameter tersebut dilakukan dengan variabel tetap sebagai berikut:

- Tekanan dijaga konstan

- Temperatur gas buat dijaga konstan.

- Pemakaian air umpan dengan tekanan konstan

Sedangkan variabel bebasnya masing-masing sebagai berikut:

- Temperatur air umpan

- Massa pemakaian bahan bakar LPG

- Jumlah produksi uap atau massa kondensat.

Data-data hasil pengujian-pengujian tersebut selanjutnya dicatat dan ditabelkan di bawah ini.

\begin{tabular}{|l|c|c|c|c|c|c|c|}
\hline No. & Pukul & $\begin{array}{c}\text { Temp. } \\
\text { air }\left({ }^{(} \mathrm{C}\right)\end{array}$ & $\begin{array}{c}\text { Tekanan } \\
(\text { Barg })\end{array}$ & $\begin{array}{c}\text { Konsumsi bb } \\
\text { LPG }(\mathrm{kg})\end{array}$ & $\begin{array}{c}\text { Kondensat } \\
(\mathrm{kg})\end{array}$ & $\begin{array}{c}\text { Temperatur } \\
\text { Gas Buang } \\
\left({ }^{\circ} \mathrm{C}\right)\end{array}$ & $\begin{array}{c}\text { Efisiensi } \\
(\%)\end{array}$ \\
\hline 1. & 16.15 & 28 & 2,96 & 1,50 & 14,8 & 283,5 & 55 \\
\hline 2. & 17.15 & 28 & 3,00 & 1,45 & 16,2 & 279,3 & 62 \\
\hline 3. & 18.15 & 28 & 3,00 & 1,45 & 15,6 & 269,3 & 60 \\
\hline 4. & 19.15 & 28 & 2,97 & 1,45 & 16,8 & 284,2 & 65,5 \\
\hline 5. & 20.15 & 28 & 3,02 & 1,40 & 16,1 & 292,2 & 63,2 \\
\hline \multicolumn{2}{|l|}{ Rata-rata : } & 28 & 2,99 & 1,45 & 15,9 & 281,7 & 60,94 \\
\hline
\end{tabular}

Tabel 3.1 Hasil Efisiensi Masing-Masing Per Jam (Variabel Tetap Tekanan)

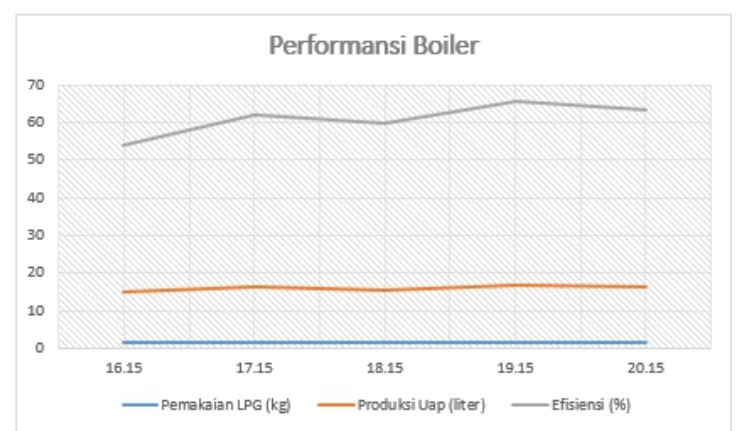

Gambar 3.2 Grafik Pada Tekanan Konstan

\begin{tabular}{|l|c|c|c|c|c|c|c|}
\hline No. & Pukul & $\begin{array}{c}\text { Temp. } \\
\left.\text { Air ( }{ }^{\circ} \mathrm{C}\right)\end{array}$ & $\begin{array}{c}\text { Tekanan } \\
(\mathrm{Barg})\end{array}$ & $\begin{array}{c}\text { Konsumsi bb } \\
\text { LPG (kg) }\end{array}$ & $\begin{array}{c}\text { Kondensat } \\
(\text { liter })\end{array}$ & $\begin{array}{c}\text { Temperatur } \\
\text { Gas Buang } \\
\left({ }^{\circ} \mathrm{C}\right)\end{array}$ & $\begin{array}{c}\text { Efisiensi } \\
(\%)\end{array}$ \\
\hline 1. & 15.45 & 28 & 2,97 & 1,45 & 14,3 & 250,7 & 55 \\
\hline 2. & 16.45 & 28 & 3,05 & 1,40 & 14,5 & 249,4 & 58 \\
\hline 3. & 17.45 & 28 & 3 & 1,50 & 14,1 & 250 & 53 \\
\hline 4. & 18.45 & 28 & 3,05 & 1,60 & 14,8 & 251,4 & 51 \\
\hline 5. & 19.45 & 28 & 3,03 & 1,50 & 14,6 & 253,7 & 55 \\
\hline \multicolumn{2}{|l|}{ Rata-rata : } & 28 & 3,02 & 1,50 & 14,5 & 251,04 & 54,4 \\
\hline
\end{tabular}

Tabel 3.2 Hasil Efisiensi Masing-Masing Per Jam (Variabel Tetap Temperatur Gas Buang) 


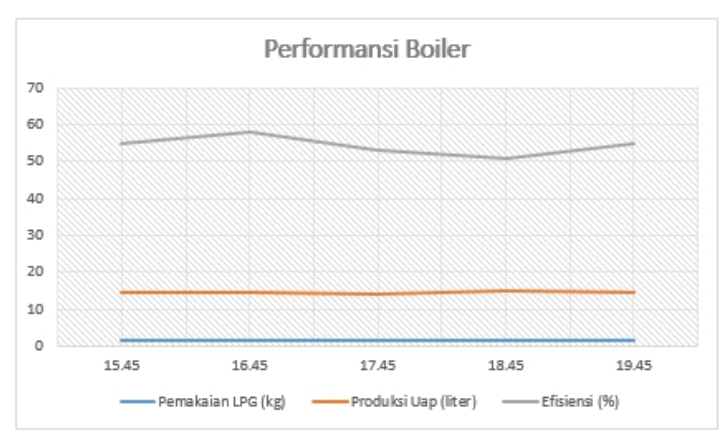

Gambar 3.3 Grafik Pada Temperatur Gas Buang Konstan

\begin{tabular}{|l|c|c|c|c|c|c|c|}
\hline No. & Pukul & $\begin{array}{c}\text { Temp. } \\
\text { air }\left({ }^{\circ} \mathrm{C}\right)\end{array}$ & $\begin{array}{c}\text { Tekanan } \\
(\text { Barg) }\end{array}$ & $\begin{array}{c}\text { Konsumsi bb } \\
\text { LPG (kg) }\end{array}$ & $\begin{array}{c}\text { Air umpan } \\
(\text { liter/jam) }\end{array}$ & $\begin{array}{c}\text { Temperatur } \\
\text { Gas Buang } \\
\left({ }^{\circ} \mathrm{C}\right)\end{array}$ & $\begin{array}{c}\text { Efisiensi } \\
(\%)\end{array}$ \\
\hline 1. & 14.10 & 28 & 2,99 & 1,46 & 16,44 & 285 & 62,0 \\
\hline 2. & 15.10 & 28 & 2,99 & 1,40 & 15,10 & 293 & 59,4 \\
\hline 3. & 16.10 & 28 & 2,98 & 1,36 & 15,50 & 297 & 62,7 \\
\hline 4. & 17.10 & 28 & 2,96 & 1,42 & 16,10 & 297 & 62,5 \\
\hline 5. & 18.10 & 28 & 3,01 & 1,44 & 15,95 & 297 & 61,2 \\
\hline \multicolumn{2}{|l|}{ Rata-rata: } & 28 & 2,98 & 1,41 & 15,8 & 294 & 61,56 \\
\hline
\end{tabular}

Tabel 3.3 Hasil Efisiensi Masing-masing Per Jam (Berdasarkan Pemakaian Air Umpan)

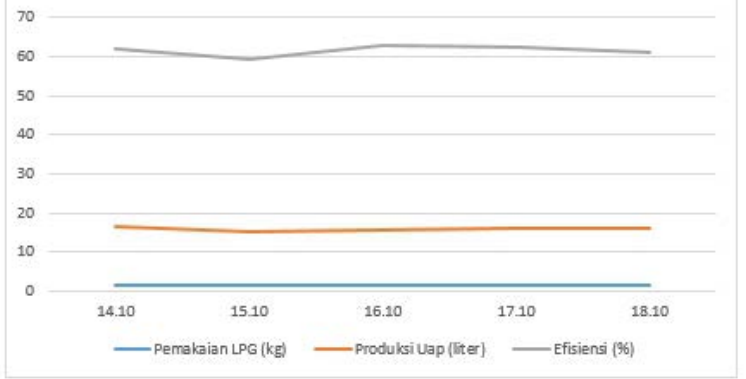

Gambar 3.4 Grafik Pada Pemakaian Air Umpan Dengan Menjaga Tekanan Tetap

I.

\subsection{Kesimpulan}

Berdasarkan hasil perancangan dan pembuatan serta pengujian Model Boiler atau ketel uap melalui analisis sumber beberapa referensi maka dapat ditarik beberapa kesimpulan sebagai berikut: 1. Pemilihan bahan bakar boiler atau ketel uap dengan cara penetapan karna ketersediaan:

- Fase bahan bakar: Gas

- Jenis bahan bakar : LPG

- Kandungan energi

- Komposisi

$\mathrm{HHV}=47081 \mathrm{~kJ} / \mathrm{kg}$

- Produksi Campuran Propana \& Butana

PT. Pertamina

2. Boiler atau ketel uap adalah alat penghasil uap dan boiler ini dasar perancangannya kapasitas produksi uap sebesar $20 \mathrm{~kg} / \mathrm{Jam}$ dan tekanannya adalah 3 barg (jenuh saturasi) dengan konsumsi bahan bakar LPG sebesar 1,5859 kg/jam atau besar kapasitas panas pembakaran 74665,758 $\mathrm{kJ} / \mathrm{jam}$. 
3. Boiler atau ketel uap dirancang dengan bentuk konstruksi horizontal mempunyai 3 (tiga) laluan atau 3-pass perpindahan panas:

Laluan pertama ( $1^{\text {st }}$-pass) atau tabung lorong api beban panas dan dimensinya:

- Jumlah Tabung lorong

$\mathrm{n}=1$ buah

- beban panas(thermal load),

$\mathrm{Q}_{1}=32232,195 \mathrm{~kJ} / \mathrm{jam}$

- luas bidang perpindahan panas,

$$
=8953,387 \mathrm{~J} / \mathrm{s}=8953,387 \mathrm{~W}
$$

- diameter tabung lorong, $d=2^{\prime}=5,7 \mathrm{~cm}$ dan

- Panjang tabunglorong,

$\mathrm{A}=0.06 \mathrm{~m}^{2}$

Laluan kedua ( $2^{\text {nd }}$-pass) terdiri dari:

- Jumlah pipa,

$\mathrm{L}=50 \mathrm{~cm}=0,5 \mathrm{~m}$

- beban panas (thermal load),

- luas bidang perpindahan panas,

- diameter tabung lorong,

$$
\mathrm{n}=6 \text { buah }
$$

- Panjang tabung lorong,

$\mathrm{Q}_{2}=13477,401 \mathrm{~kJ} / \mathrm{jam}=3743,7225 \mathrm{~W}$

$\mathrm{A}=0,136 \mathrm{~m}^{2}$

Laluan ketiga ( $3^{\text {nd }}-$ pass) terdiri dari:

- Jumlah pipa,

$=1,905 \mathrm{~cm}$

- beban panas (thermal load),

- luas bidang perpindahan panas, $\mathrm{A}=0,120 \mathrm{~m}^{2}$

- diameter tabung lorong, $\mathrm{d}=3 / 4^{\prime}=1,905 \mathrm{~cm}$

- Panjang tabung lorong, $\mathrm{L}=50 \mathrm{~cm}=0,5 \mathrm{~m}$

$$
\mathrm{L}=50 \mathrm{~cm}=0,5 \mathrm{~m}
$$

Setelah perancangan selanjutnya dilaksanakan fabrikasi dan pemasangan ketel pipa api dan alat-alat pendukungnya di salah satu bengkel di Jalan Mahkamah Kota Medan.

4. Hasil-hasil penelitian melalui pengujian model boiler atau ketel pipa api yang dilaksanakan di rumah sendiri diperoleh:

masing-masing setiap 1 jam selama 5 jam atau 5 kali berturut-turut.

- kapasitas uap rata-rata,

Q̀ $=15,4 \mathrm{~kg} / \mathrm{jam}$

- konsumsi bahan bakar LPG rata-rata,

$\dot{\mathrm{m}}_{\mathrm{bb}}=1,45 \mathrm{~kg} / \mathrm{Jam}$

- tekanan kerja operasi

- temperatur air umpan masuk,

$\mathrm{p}=4$ bar absolut

$\mathrm{Ta}=28{ }^{\circ} \mathrm{C}$

- efisien boiler (rata-rata)

Pada tekanan konstan

$\eta \quad=$

$60,94 \%$

Pada temperatur konstan

$\eta=54,4 \%$

5. Pada penelitian model ketel pipa api ini untuk kerja tekanan dijaga konstan selama 5 jam dimana setiap satu jam berturut-turut dihitung besarnya efisiensi diperoleh antara $55 \%$ - 65,5\% dan untuk temperatur gas buang dijaga konstan selama 5 jam dimana setiap satu jam berturut-turut diperoleh antara 51\% - 58\%.

6. Dari hasil penelitian ternyata performansinya lebih rendah dari spesifikasi perancangan dan ini terjadi karena faktor-faktor pembuatan (pemotongan dan pengelasan), jenis bahan-bahan yang digunakan, tidak diperoleh dengan benar-benar akurat dari pihak pekerja dan penjual.

\subsection{Saran}

Dari hasil perancangan dan pembuatan model ketel pipa api ini, maka disarankan antara lain sebagai berikut: 
1. Agar Jurusan teknik mesin fakultas teknik usu dapat membuat model-model ketel uap untuk dapat dimanfaatkan mahasiswa untuk percobaan-percobaan atau pengujian-pengujian sehingga menghasilkan lulusan yang memiliki kompetensi di bidang ketel uap.

2. Karena uap penggunaannya sangat luas sehingga produksi uap yang dihasilkan ketel pipa api dapat dimanfaatkan untuk beberapa percobaan-percobaan yang berkaitan dengan sistem energi uap, misalnya: pengujian kualitas uap, sistem pengukuran aliran uap, percobaan turbin uap, dan lain-lain.

\section{DAFTAR PUSTAKA}

[1] Holman J. P. Heat Transfer. 5th Edition. Mc-Graw Hill,Ltd. Thermodynamics. Mc-Graw Hill,Ltd

[2] Kinsky, Roger. ( 1989 ). Heat Engineering. 3rd Edition. Australia : McGraw - Hill Book Company

[3] Muin, Syamsir A. ( 1988 ). Pesawat-pesawat Konversi Energi (I) : Ketel Uap. Ed. 1, Cet. 1. Jakarta : Rajawali

[4] Weisman, Joel \& Eckart, Roy. (1985 ). Modern Power Plant Engineering. New Jersey : Prentice-Hall, Inc., Englewood Cliffs

[5] Reynolds, William C. \& Perkins, Henry C. Engineering Thermodynamics. 2nd Edition. McGraw Hill, Inc 